\title{
A Systems Approach to Improve Performance in Supply Chain: Case Study in a Procurement Process in the Aeronautical Industry
}

\author{
Denis Olmos-Sanchez, Jean-Claude Bocquet \\ and Marie-Agnès Forman
}

\begin{abstract}
Supply Chains (SC) are becoming more complex by the interaction of various elements, and decisions must be taken at different levels to accomplish their objectives. Several approaches propose performance improvements but there is a lack of application of systemic approach to maximize the value creation. In this work, we apply a method called SCOS' (Systemic for Complex Organizational System) which focuses in reaching new objectives in terms of value creation (performances as economic, quality, time and environment) for each phase of the life cycle, and each stakeholder of the system (procurement process), then processes are developed to meet these finalities. A case study is used to model value creation in an SC as an improvement expected by stakeholders, and it is validated by industrial experts. Then recommendations are given to simulate and quantify these improvements through system dynamics.
\end{abstract}

Keywords Systemic approach - Modeling - Supply chain performance • Procurement • Improvement • Aeronautical industry

D. Olmos-Sanchez $(\bowtie) \cdot$ J.-C. Bocquet

Laboratoire Génie Industriel, CentraleSupelec, Campus Châtenay-Malabry Grande voie des

Vignes, 92295 Châtenay-Malabry, France

e-mail: denis.olmos@centralesupelec.fr

J.-C. Bocquet

e-mail: jean-claude.bocquet@centralesupelec.fr

M.-A. Forman

Dassault Aviation, 78 Quai Marcel Dassault, 92210 Saint-Cloud, France

e-mail: marie-agnes.forman@dassault-aviation.com 